Mental Handicap: A Community Service. By Nick Bouras, Katie Drummond, David Brooks and Matt Laws. NUPRD, Lewisham Hospital, London SE13. 1988. Pp. 47. £5.00.

Community Mental Handicap Teams, initiated a decade ago by the National Development Team for Mental Handicap, have become a popular means whereby the health care skills of team members are made available to people with a mental handicap (or learning difficulties), living in the community. Such community teams have two main roles, firstly to make ordinary health care more easily available to people with a mental handicap and secondly, community teams offer specialist health care contributions from the many disciplines represented within the team. Much ordinary health care can be made accessible to the patient by advocacy, by education and training and by changing attitudes in ordinary health care services. However, some of the disorders are so complex and long standing that a specialist service is required.

The contribution of the psychiatrist in this team can be seen in both of its roles. He works closely with his generic psychiatric colleagues in the treatment of those with a mild mental handicap and mental illness and he may have equal user status in the general psychiatric unit. Those who are more handicapped and have challenging behaviours rather than mental illness are cared for in the service for people with severe mental impairment.

Prior to the development of community teams, health care resources were channelled mostly to the large long-stay hospitals but the track record for the delivery of health care was never good: many studies showed a poverty of primary care, health promotion and even psychiatric intervention. These individuals are now moving from their long-stay hospitals into the community and bringing with them not only years of inadequate health care but the damage that has been done by institutionalisation. It is these people, together with those who have never lived in institutions, that comprise the client group that the authors of this booklet work with today.

Many psychiatrists who work in such teams find themselves overwhelmed by the needs uncovered, that time is not set aside for evaluation by quality assurance or by monitoring. Dr Bouras and his colleagues from Guy's Hospital have created a community based psychiatry of mental handicap component within the multidisciplinary team in one health district of South East London and have taken the initiative, as outlined in this booklet, to share with us the first five years of the service.

The document analyses the referrals from the first five years of the team's work, presenting demographic, medical and sociological data and concentrating on the psychiatric need that was uncovered. As expected, psychiatric illnesses were harder to identify than people with profound, severe or moderate mental handicap, while many mildly mentally handicapped people had easily recognisable psychiatric disorders. The point is correctly made that this is a study of individuals referred for help rather than an epidemiological study and so prevalence data are not available.

This survey is important for several reasons; it is probably the first of its kind to be made available to a wide audience; and attempt is made to provide objective data of the symptomatology of people with mental handicap and mental illness; the proposed model of care is clearly outlined before it is known whether it will be entirely successful or not, and finally, there is a multi-dimensional or multi-axial approach which should provide useful information for the multi-centre trial of multi-axial classification that is being co-ordinated at present by the College.

Increasingly within such a multidisciplinary team, a developmental model or, more exactly, a 'skills and needs' model is being used to ensure that all those who need help in their development have some form of assistance and that not all the resources are geared to crisis intervention. There may be some difficulty in integrating the problem solving approach from the psychiatrists and the developmental model as described above, but this is surely a challenge we must accept.

If more teams (including my own) were to set time aside for such an honest appraisal of the early years of a team, our knowledge of the psychiatric needs of those people with a mental handicap who have always lived in the community and those who are coming out of institutions to join them, would be a lot more substantial.

Professor of Psychiatry of Mental Handicap

St George's Hospital Medical School

London SW17

South West Psychiatry: A postgraduate journal published half-yearly under the SW Regional Vocational Training Subcommittee, edited by H. G. Morgan.

\section{DeAR Gethin}

Through the post this morning came the first issue of South West Psychiatry and, as you say in your editorial, one queries "the wisdom of embarking on yet another regular psychiatric publication." It can so easily be a depository for poorly informed misleading papers and minimally thought-out ideas, which simply boost the self-esteem of authors who see themselves in print. Well, we can always throw it in the bin. Yes, but it does a dis-service to psychiatry. I have seen it happening elsewhere-people making 
clinical studies or writing reviews, who take the easy way, do too little work too quickly, because they know the X Journal will always publish it. Yet with a bit more effort and self-discipline they were capable of doing work properly, getting it into a proper journal, and even contributing to psychiatric practice instead of to the rubbish mountain. As an ex-editor (over $\mathbf{4 0}$ years!) I think one may be able to avoid this pitfall, but it means a great deal of editorial work, which I don't see in issue no. 1.

Take your 'Invited Review', for instance. It isn't a review, its a sort of annotation or leaderette, and it reads to me confused. Phil Seager is an old friend of mine, and I admire as well as like him. He's obviously pretty busy as Director of the HAS, and worried by its problems, and here he seems to be asking himself two questions and not finding the answers (1) What is a medical model and is it ever appropriate - if so, how far? (2) When is a client a patient, and vice versa? These are two important questions, I think you should have (a) got the text clarified (b) invited a social worker, a nurse, a psychologist to give their views at the same time, made it a stimulating discussion with clear pros and cons.

This raises another point. Is the new journal just for psychiatrists or for all members of the team? There might be a place for a truly interprofessional journal, explaining each to the others. I know you have a non-medical contribution on a community mental health centre; it could have been so much more informative to the medical reader with some editorial guidance.

The history of Mendip Hospital, Wells, contains interesting material, but why no guidance on where to read more about it, or how to study the history of one's own hospital (e.g. see Annual Reports); why no comparison with what has been written about other hospitals (Psychiatry for the Poor by Hunter \& Macalpine, Dawsons (1974), Museums of Madness by Andrew Scull, Penguin (1982), etc); why stick to the amusing anecdote instead of educating? Asylum histories can teach old answers to current problems of how to run a mental health service.

Your remark about the geography of the southwest requiring a special journal to bring psychiatrists together puzzles me. Why won't the Psychiatric Bulletin or the British Journal of Psychiatry do? Is there something special about the rural schizophrenics of Dartmoor or the psychopaths of Torquay which we in the rest of Britain won't understand? Or are you planning advertisements of the type "young Cornish psychiatrist would like to meet similar with view to companionship and study for membership"?

I think your plan to encourage single case reports by registrars, and critical literature reviews by nonconsultants is in principle excellent, and could be a real addition to training. But to be any use I am sure much editorial guidance will be needed: getting full but only relevant information in the cases; choosing subjects for the reviews and suggesting questions for answer in them to prospective authors, as well as revision at the end.

Of course it's not fair to judge anything on the first issue. I criticise because I want you to succeed, it's a way of wishing you well. A committee can't produce a good journal, it has to be a positive expression of one person's outlook and taste: as Eliot Slater, Cyril Connolly and others testify.

Emeritus Reader in Biological Psychiatry

JOHN CRAMmer

Institute of Psychiatry

London SE5

\section{DEAR JOHN}

Thank you for your letter about the first number of South West Psychiatry. You have taken much trouble to give us valuable advice based on your extensive experience as an editor, and we are most grateful for your guidance. There are several points on which I am keen to reply.

You clearly are concerned that we might merely encourage material of poor standard, thereby adding to the 'rubbish mountain'. Our Editorial Board is very mindful of such a danger, and has no intention of wasting its time, or that of its readers, by promoting the publication of low quality papers. Let me point out the role that we envisage for our Journal; it is spelt out in our first number, but it seems that you are not entirely clear on this point which certainly is not made apparent in your letter.

South West Psychiatry is intended to have a local circulation within the South West Region. One of its main aims is to stimulate trainee psychiatrists to begin thinking critically about their work, and to express this in writing. Are you not worried, after $\mathbf{4 0}$ years as editor, about the reluctance which many trainees show in taking the very first steps in this direction? Do you not share my concern that psychiatric training is at risk of merely encouraging the absorption of facts and subsequent application of given truths? South West Psychiatry will try to act as a catalyst at a very early stage, without claiming copyright, in the hope that trainees might submit preliminary reports and abstracts to us, and then subsequently develop their ideas further for submission of papers to a national journal. The current editor of the British Journal of Psychiatry has in fact welcomed this approach.

The role of South West Psychiatry throughout our Region also needs comment. Your quip about trainees in Cornwall getting together is touching but nearer the truth than you might realise. Now that services have been sectorised, clinical psychiatry can be a lonely business. As someone who travels the length of the South West Region more regularly than 